\title{
Los puntos cardinales y Circomística de Angélica Murillo
}

Selene Fallas Salazari, Universidad de Costa Rica

Recibido: 4/08/2014.

Aceptado: 18/03/2015

\section{Resumen}

Este artículo hace una lectura del poemario Circomística de Angélica Murillo y analiza algunos puntos de la obra para entender cómo la estructura del texto contribuye a organizar el sentido. Se establece una metáfora entre las cuatro partes del libro y los cuatro puntos cardinales.

\section{Abstract}

\section{The Cardinal Points and Circomística by Angélica Murillo}

This paper is intended to give a particular reading to the poem book Circomística by Angélica Murillo and analyzes some features of her work in order to understand how the structure of the text contributes to organizing meaning. A metaphor is developed between the four parts of the book and the four cardinal points.

El presente artículo hace una lectura del poemario Circomística de la poeta costarricense Angélica Murillo.

En vista de su reciente publicación, aún no existe material con el cual dialogar, pues no se ha publicado hasta ahora ninguna crítica literaria sobre él. Así las cosas, la primera hipótesis central que se plantea en este artículo, señala que la expresión del texto poético ocurre por medio del lenguaje; en otras palabras, la manifestación de conjunto del significante provoca una especie de ilusión referencial y sugiere formas e imágenes en los poemas.

Partiendo de esta hipótesis, el análisis Ileva a una lectura de las significaciones o desciframiento del sentido del objeto de estudio. Entonces, los niveles de enunciación que constituyen el armazón de la semiótica, la fijación de las ideas centrales derivadas de los núcleos o el análisis sémico, todo ocurre alrededor de las redes relacionales de dicho texto.

i Selene Fallas es licenciada en Literatura y Lingüística con énfasis en Literatura, graduada de la Universidad Nacional de Costa Rica. Está egresada de la Maestría en Literatura Latinoamericana de la Universidad de Costa Rica. Trabaja en el Instituto de Investigaciones Psicológicas de la Universidad de Costa Rica y como profesora de Enseñanza del Castellano y Literatura, en esa misma universidad.

Selene Fallas Salazar. Los puntos cardinales y Circomística de Angélica Murillo. Revista Comunicación. Año 36, vol. 24, núm. 1. Enero - julio, 2015. Tecnológico de Costa Rica. ISSN Impreso: 0379-3974/ e-ISNN: $1659-3820$

\section{PALABRAS CLAVE:}

Poesía costarricense, lectura, Circomística, Angélica Murillo.

\section{KEY WORDS:}

Costa Rican poetry, reading, Circomística, Angélica Murillo. 
Asimismo, se analizará el título del poemario, formado por una palabra compuesta y un neologismo, y su respectivo significado.

El Diccionario de la Real Academia de la Lengua Española (RAE) brinda nueve acepciones para la palabra circo. Seguidamente citaré algunas:

Circo (Del lat. circus). 1. m. Edificio o recinto cubierto por una carpa, con gradería para los espectadores, que tiene en medio una o varias pistas donde actúan malabaristas, payasos, equilibristas, animales amaestrados, etc. 2. m. Este mismo espectáculo. 3. m. Conjunto de artistas, animales y objetos que forman parte de este espectáculo. 4. m. Conjunto de asientos puestos en cierto orden para los que van de oficio o convidados a asistir a alguna función. 5. m. Conjunto de las personas que ocupan estos asientos. 6. m. Lugar destinado entre los antiguos romanos para algunos espectáculos, especialmente para la carrera de carros o caballos. 9. m. coloq. Confusión, desorden, caos. (RAE, 2013).

Con respecto al término místico, la RAE brinda tres acepciones:

Místico (a) (Del lat. Myst ca). 1. f. Parte de la teología que trata de la vida espiritual y contemplativa y del conocimiento y dirección de los espíritus. 2. f. Experiencia de lo divino. 3. f. Expresión literaria de esta experiencia. (RAE, 2013)

Al juntar ambas definiciones, puede afirmarse que la circomística es la expresión literaria de la experiencia divina, encerrada dentro del espacio circense. Por su parte, el término "circo" es claramente y en todas sus acepciones masculina, mientras que la palabra mística es en todas sus acepciones femenina; al juntar entonces estas dos palabras se da algo más: es unión de las miradas, las formas de entender y narrar desde dos principios: el masculino y el femenino. Así como en el circo ocurre un espectáculo que convoca y mezcla a diferentes artistas, la circomística es también un espacio de confluencias, donde se dan cita varias visiones de mundo y de poesía, la poesía que es, en realidad, solo otra forma de entender y de vivir la vida.

El circo funciona como un espacio que, en términos de Lotman (1981), posee rasgos distintivos propios de un espacio cerrado en sí mismo. Por ende, el universo lírico se centra en este espacio y marca un límite espacial.

Seguidamente se hará un recorrido por todo el poemario, el cual está dividido en cuatro partes. Esto podría tener algún significado (o tal vez no), pero sería injusto creer que un autor utiliza el escalpelo de manera aleatoria o antojadiza, lo más factible es que esta disección quiera llamar la atención.

Chevalier (1986) afirma que las significaciones simbólicas de los textos son importantes para el análisis literario, por tanto, aquí se partirá de esta afirmación. Según lo planteado por este escritor, se iniciará con el estudio del número cuatro. El cuatro es, símbolo de universalidad y plenitud, pues la tierra está dividida por un meridiano y un paralelo en cuatro sectores. Son cuatro los puntos cardinales, los vientos, los pilares del universo, las fases de la luna, las estaciones, los elementos, los humores, los brazos de la cruz. La vida humana se divide en cuatro colinas: la infancia, la juventud, la madurez y la vejez. El número cuatro representa a la Tierra y al igual que ella no crea, sino que contiene la creación (Chevalier, 1986, p. 380).

El arte, como explica Lotman (1981), es un sistema de signos que van ordenados de manera particular y buscan unidades de referencia que permitan desarticular el sentido de esos mismos signos, los cuales se semantizan o resemantizan para ordenar el texto en un espacio encerrado en sí mismo, como símbolo dentro de un sistema.

El arte también es un sistema comunicativo que crea un lenguaje, donde un artista selecciona la forma de comunicar un mensaje a un lector, a partir de ciertos signos. El artista semantiza todo, o sea, carga de sentido un signo $y$, de este modo, organiza el texto. Lotman (1970) explica esta condición atribuyéndole a la semiosfera un rasgo distintivo: su carácter delimitado, que la separa de los sistemas extrasemióticos o alosemióticos, ubicados en el espacio exterior que la rodean (Lotman, 1981).

Así las cosas, el libro está ahí: extenso y abierto para caminar sobre él y para que los lectores pueden jugar a demiurgos al sentidos y relaciones y al convertirse en espectadores activos de él.

\section{EL NORTE}

La primera parte del libro se compone de cuatro poemas: "La Orquesta", "El Maestro de Ceremonias", "El 
Mago" y "El Trapecista". Estos parecen apuntar a una dirección y a un color, pues en el texto se ha dicho que el Norte se viste de negro. Para allá parece ir la autora: hacia un norte que ofrece un sentido, un segmento del circo.

La orquesta se impone como el primer elemento circense que la autora revela. En el circo la música es un elemento de suma importancia. Seibel (2005) lo destaca y es esa particular orquesta la que anima y predispone el juicio para apreciar el acto que se ejecutará en escena. En este caso, la orquesta pretende revelar un secreto o, más bien, lanza una advertencia: el circo es una cárcel: "ese antro donde el duende nos tiene presos" (Murillo, 2013, p. 15). La música es un augurio que el mismo circo devora, pues atrae a todos como el flautista de Hamelín. Esta música crece en confusión y al final, devora a quien entró a su jaula. ¿Será que la existencia humana tendrá el mismo propósito o destino? Esta podría ser la primera gran inquietud que plantea la autora.

El segundo poema "El Maestro de Ceremonias" hace directa alusión a los cuatro puntos cardinales. Recuérdese que aún no se ha salido de la primera sección, "El norte", y que según Chevalier (1986) es el punto más negro.

La figura del maestro de ceremonias se anuncia como una suerte de guardián de los muertos que alguna vez visitaron el circo:

$$
\begin{gathered}
\text { Eres un bastón en el ático } \\
\text { del tiempo } \\
\text { inútil vigilante de no sé } \\
\text { qué tumba (Murillo, 2013). }
\end{gathered}
$$

Este maestro de ceremonias atemporal y eterno, es quien guarda en sus ojos las sillas, ahora vacías.

El tercer poema se denomina "El Mago". Se trata de un ilusionista que nos permite volver a la infancia y al mismo tiempo, puede asegurarse de que esta etapa de la vida viene a ser un refugio para esconderse de la muerte, una butaca cronotopo que permite mantener la esperanza.

El cuarto y último poema de El Norte se denomina "El Trapecista", el cual se presenta como un personaje oscuro y asfaltado, el negro, que se evidencia sigue reinando al norte de nuestra existencia. El trapecista es:

$$
\begin{gathered}
\text { araña que va } \\
\text { viene } \\
\text { sube } \\
\text { baja (Murillo, 2013). }
\end{gathered}
$$

El trapecista realiza cuatro movimientos, se mueve en cuatro direcciones y permanece en cuatro estancias:

$$
\begin{gathered}
\text { Cuatro veces pasó } \\
\text { el gatopardo } \\
\text { crispó sus uñas afiladas, } \\
\text { su luna } \\
\text { tejida de asfalto (Murillo, 2013). }
\end{gathered}
$$

El trapecista también fue consumido, mientras el sádico trapecio ríe y la niña llora. Los dos extremos vida y muerte, risa y llanto son la síntesis de la vida, del circo y de las criaturas que lo conforman y lo observan.

\section{EL SUR}

La segunda parte del libro empieza con la figura de "El Arquero". De acuerdo con Chevalier (1986), "el arquero es el símbolo del hombre que apunta a alguna cosa y que ya, en cierto modo, la alcanza en efigie". En este caso específico, e arquero apunta hacia al lector:

$$
\begin{gathered}
\text { Y esta flecha que cruza } \\
\text {-no sé de dónde- } \\
\text { hoy halló tu carne }
\end{gathered}
$$$$
\text { su verdadero blanco (Murillo, 2013). }
$$

Al sur, Chevalier (1986) le asocia el color rojo y señala que para los náhuatl es el lado de las espinas y de la sangre "que nos baña", lo cual calza perfectamente con la flecha que recién recibimos.

El segundo poema de El Sur es "El Titiritero". Este texto se encuentra fragmentado en tres partes. La primera presenta a un hijo animado por un brazo:

$$
\begin{gathered}
\text { sé que mi brazo } \\
\text { es la madre que esparce } \\
\text { el aliento entre sus hilos (Murillo, 2013) }
\end{gathered}
$$

La segunda presenta a un títere que es un doble: "De pronto su furia me rompe las manos" (Murillo, 2013). Es una da dualidad del artista creador y verdugo de su obra. Esclavo y amo de su arte.

La tercera parte concluye o resuelve a favor de quien mueve la mano:

\section{No lo olvides}

marioneta:

Eres monedero de este hilo aliento

entre el aliento que se quema (Murillo, 2013). 
El tercer poema se denomina "Femina Circus". Se presenta acá una suerte de bailarina que se mueve entre los extremos del circo: vida y muerte; mujer objeto, casi títere y esclava, como todos, del absurdo:

$$
\begin{gathered}
\text { Y no existe } \\
\text { el pájaro animal } \\
\text { libre }
\end{gathered}
$$

que buscabas (Murillo, 2013).

El cuarto poema, "Ideograma de los Siameses" muestra la figura de un juez, un observador, un delator que espera con ansias el momento de hablar y condenar. De nuevo parece retratar al artista y su obra, en una relación de víctima y verdugo:

\section{Pero un día-o una noche cualquiera- como un fragmento de luz desconocido sabrás que yo soy}

el vínculo vital que te condena (Murillo, 2013).

Esta relación siamesa entre el autor y su criatura, que no da espacio al bisturí, es irrevocable y los vuelve uno: fenómeno social, atracción circense.

El quinto y último poema de esta segunda parte se presenta bajo la figura de "El domador". Este se asemeja al arquero del primer poema de esta parte, en tanto que poseer es domeñar (afirma el poema). Tanto el arquero como el domador logran someter a la fiera, que en parte es una extensión de sí mismos. El león furioso que el domador no teme, porque sabe que el animal entiende también que la jaula es la misma. Sin necesidad de mediadores, ambos juegan el juego y cumplen con un rol preestablecido. El látigo del tiempo es el único que impera para todos y la muerte es la jaula irrenunciable que siempre nos asecha. Este último poema también alude al rojo.

\section{EL ESTE}

La tercera parte se enmarca como un intermedio, es decir, una pausa para el circo, pero no para el espectador. El primer poema: "Excursión circense al puerto" parece llevarnos a un nuevo destino, ¿hacia dónde gira esta vez la brújula? Pues parece que al Este, donde el payaso y el mar protagonizan esta excursión. El payaso, figura central del circo, se muestra fuera de la carpa, prófugo de una realidad que quiere anclarlo, pero él logra escapar, al menos, temporalmente:

$$
\begin{gathered}
\text { y hoy, } \\
\text { un día como ayer }
\end{gathered}
$$

\author{
también vira la barca \\ ocultando al prófugo de los mapas \\ (Circomística, p. 38).
}

El segundo poema de esta tercera parte, Ilamado "Monólogo de las cosas inverosímiles (En una maleta a la orilla de una playa)", parece que arroja un poco de esperanza, no en vano, el este es el punto cardinal donde sale el sol y por ende la esperanza. Empero, la ilusión es tenue, casi gratuita como "Un imaginario tajamar". La vida se encarga de consumir al ser humano, aunque el poema intente construir alguna ilusión:

Quedan las algas, la espuma la acuática polilla (Circomística, p. 40).

El tercer y último poema de El Este, de este intermedio, que nos deja salir de la carpa, pero nos obliga a volver para el final, se titula "Siete maneras de crear un circo".

El texto se divide en siete partes, lo cual parece proponer una analogía con el relato de la creación de la tradición judeo-cristiana narrada en la Biblia, que también se desarrolla en siete momentos. El primero de estos escenarios requeridos para la creación del circo está constituido por "Un poeta". Al igual que en el mito judeocristiano, quien enuncia la palabra protagoniza el principio de la cosmo génesis. El poeta es concebido como el creador, quien da origen al mundo circense propuesto en este texto:

$$
\begin{aligned}
& \text { verbo insondable donde el verso } \\
& \text { acaba (Circomística, p. 41). }
\end{aligned}
$$

La segunda figura en este orden es "El bufón", destinado siempre a la risa y que provoca una interrogante: "¿Quién da saltos en la cuerda floja?". La risa y no el acertijo se relacionan tradicionalmente con este personaje, sin embargo, ya Shakespeare utilizaba al bufón para plantear las propuestas más serias.

La tercera efigie en esta cosmogonía es un saltimbanqui, elemento que también parece condenado a un destino:

En el centro o en la orilla en la tierra o en el agua de su eje no se escapa (Circomística, p. 42).

La cuarta imagen de esta génesis se contrapone, al menos conceptualmente, con las anteriores: "Un pesimista" se anuncia con redoble de tambor y termina con 
su profecía autocumplida; entra temiendo lo peor y cae, en su momento de gloria, durante su número.

La quinta figura de esta creación corresponde a "Un vengador" quien nos lanza un nuevo acertijo:

¿Dónde

la garganta falaz

o el puñal de la furia? (Circomística, p. 43).

La venganza se ejerce con la palabra (garganta falaz) o con el hierro afilado (el puñal de la furia), pero acá la pregunta sería ¿dónde está esa furia? O también, ¿dónde están esas armas?, ¿dónde aplica la voz o el cuchillo de la venganza?

La sexta representación de este mundo resuena en la primera "Un eco":

$$
\begin{gathered}
\text { mientras...entras } \\
\text { mueres...eres (Circomística, p. 43). }
\end{gathered}
$$

Sin duda el juego de palabras y la onomatopeya resultan inquietantes, y su mensaje aún más: hay que entrar al circo y hay que morir para ser. Por eso esta última figura se relaciona claramente con el descanso bíblico del sétimo día: "El silencio" la carpa dormida es la última versión de esta cosmogonía, es la última imagen de su creación, su esencia final.

\section{EL OESTE}

Ahora, irremediablemente, el Oeste, el cuarto y último punto cardinal, donde el trayecto cierra el libro y aparece una cruz mística envuelta en una carpa. En esta parte, el primer poema remite a una figura muy importante del circo: "El Espectador". La siguiente metáfora parece encerrar el papel que cumple el espectador, el circo, el arte, la vida, la poesía, cárceles todas que fingen abrir sus puertas y terminan consumiendo al ser humano, pero que igual, se corre hacia a ellas:

Y el insecto ofrenda sus membranas a la llama aun sabiendo que un golpe de su dedo

le mutila (Murillo, 2013).

El segundo poema, Ilamado "El hombre bala", presenta una figura que es más una estela o más bien, "materia luminosa que no se desplaza" (Murillo, 2013). Se nos despliega como el resplandor de su propia marca, pero trae consigo la sospecha de que se mueve y al mismo tiempo que la certeza de la imposibilidad de que se mueva.
También trae la sospecha de que se vive, junto con la certeza de que cada día camina (¿caminamos?) hacia nuestra propia muerte.

El segundo poema de esta parte final es "Pantomima en el espejo". También se divide en dos partes. La primera parece ser la voz del espejo que se adueña del aliento:

\section{Mío es \\ el aliento \\ de los mendigos}

la corteza cíclica y el reflejo de la sombra (Ibid.,54).

Es el espejo quien secuestra al mimo, con su disfraz algebraico: ¿Será ese espejo el disfraz o la sombra?

La segunda parte da la impresión de ser enunciada por el mimo, quien parece desear un escape de su destino, de ese horizonte que lo engaña y niega la verdad escondida por el espejo:

Horizonte que no era

el rostro en el espejo (Murillo, 2013).

El tercer poema, "La esquizofrénica enjaulada", retrata el juego de espacios cuando el circo se hace realidad y cuando esta, se vuelve un circo:

$$
\begin{gathered}
\text { Hacia otras furias } \\
\text { su miedo le conduce, } \\
\text { parajes }
\end{gathered}
$$

casi amorfos de tanto circo( Murillo, 2013, p. 57).

La jaula viene a ser un símbolo de aislamiento (Chevalier, 1986), aunque también es un destino común. No solo se "enjaula" aquello que amenaza, también lo que se ama y no se quiere perder. La jaula en este caso, es el reflejo de lo que no se quiere revelar, de lo que debe estar cifrado para los ojos curiosos del niño:

$$
\begin{gathered}
\text { Aunque, la jaula no impida el contacto: } \\
\text { maligno será el beso } \\
\text { que vertí en su llaga (Murillo, 2013, p. 57). }
\end{gathered}
$$

El quinto poema "El traga-fuego" ofrece una figura enigmática: "pero soy esa fiera que ajena permanece a toda luz". Gracias a este, la vida entra en una bocanada de fuego o aire, la intensidad del momento:

$$
\begin{gathered}
\text { Por un instante } \\
\text { poseo la sensación } \\
\text { de que } \\
\text { respiro (Murillo, 2013, p. 59). }
\end{gathered}
$$


Finalmente, el poema con que finaliza este libro, es "El circo". Se concluye con esta metáfora del circo como espacio de encierro, la carpa parece invitar, pero es en realidad un cáliz ineludible, de donde no hay escapatoria:

$$
\begin{aligned}
& \text { Siéntelo: Es el pecho atormentado } \\
& \text { de los recién } \\
& \text { nacidos (Murillo, 2013, p. 60). }
\end{aligned}
$$

Al terminar de leer Circomística se puede concluir que en el neologismo "circomística" se unen dos miradas, dos formas de entender y narrar desde dos principios: el masculino y el femenino.

El texto se divide en cuatro partes y cada una de ellas apunta o puede leerse desde un punto cardinal: la primera parte corresponde al norte, la segunda al sur, la tercera al este y la cuarta al oeste. En cada punto cardinal se encuentran los elementos requeridos para que cada parte del libro se lea como una dirección. El circo, resulta más inquietante, las carpas ahora parecen un abismo, un espacio que convida a enamorarse de la muerte. Hay oscuridad en todas las direcciones y la misma sensación de desamparo y desolación envuelve toda la carpa del circo, como una metáfora del mundo circundante.
El poemario se convierte en una semiosfera, en tanto espacio cerrado, pero sensible a permear y dejarse influir por lo que está fuera. Por último, el espacio construido se cierra en los cuatro puntos cardinales, la carpa del Circo se enmarca y, como explica Lotman (1981), el texto crea una organización interna que lo separa o enmarca de todo lo que le rodea.

\section{REFERENCIAS BIBLIOGRÁFICAS}

Chevalier, J. (1986). Diccionario de símbolos. Barcelona: Herder.

Lotman, I. (1970). La estructura del texto artístico. Madrid: Istmo.

Lotman, I. (1981). La semiosfera I, Semiótica de la cultura y del texto. Madrid: Cátedra.

Lotman, I. (1981). La semiosfera III, Semiótica de las artes y de la cultura. Madrid: Cátedra.

Murillo, A. (2013). Circomística. San José: Espiral.

Real Academia de la Lengua Española (2013). Diccionario de la Lengua española. Versión digital del 18 de agosto de 2013.

Seibel, B. (2005). Historia del circo. Buenos Aires: Del Sol. 